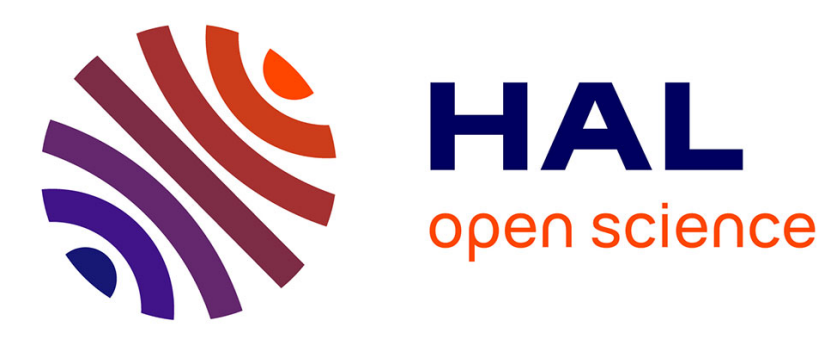

\title{
Virtual reality to assess and train team ball sports performance: A scoping review
}

\author{
Charles Faure, Annabelle Limballe, Benoit Bideau, Richard Kulpa
}

\section{To cite this version:}

Charles Faure, Annabelle Limballe, Benoit Bideau, Richard Kulpa. Virtual reality to assess and train team ball sports performance: A scoping review. Journal of Sports Sciences, 2020, 38 (2), pp.192-205. 10.1080/02640414.2019.1689807 . hal-02442089

\section{HAL Id: hal-02442089 \\ https://hal.inria.fr/hal-02442089}

Submitted on 16 Jan 2020

HAL is a multi-disciplinary open access archive for the deposit and dissemination of scientific research documents, whether they are published or not. The documents may come from teaching and research institutions in France or abroad, or from public or private research centers.
L'archive ouverte pluridisciplinaire HAL, est destinée au dépôt et à la diffusion de documents scientifiques de niveau recherche, publiés ou non, émanant des établissements d'enseignement et de recherche français ou étrangers, des laboratoires publics ou privés. 


\section{Virtual reality to assess and train team ball sports performance: A scoping review}

\section{Charles Faure, Annabelle Limballe, Benoit Bideau \& Richard Kulpa}

To cite this article: Charles Faure, Annabelle Limballe, Benoit Bideau \& Richard Kulpa (2019):

Virtual reality to assess and train team ball sports performance: A scoping review, Journal of Sports Sciences, DOI: 10.1080/02640414.2019.1689807

To link to this article: https://doi.org/10.1080/02640414.2019.1689807

\section{曲 Published online: 14 Nov 2019.}

Submit your article to this journal

Q View related articles $₫$

View Crossmark data $\nearrow$ 


\title{
Virtual reality to assess and train team ball sports performance: A scoping review
}

\author{
Charles Faure $\mathbb{D}$, Annabelle Limballe, Benoit Bideau and Richard Kulpa
}

Sport and Exercise Department, Univ Rennes, Rennes, France

ABSTRACT

Virtual reality (VR) is a widespread technology drawing an increasing interest for players and coaches, especially in team ball sports as it offers a simple tool to simulate, analyse and train situations that are often too complex to reproduce in the field. In this review we aimed at (1) providing an overview of methodologies and outcomes of research studies using VR in team ball sports; (2) better evaluating the potential interest of VR to analyse or train team ball sports situation and (3) identifying limitations, gaps in knowledge and remaining scientific challenges. The MEDLINE and Web of Science Core Collection databases were searched, using predefined combinations of keywords. Thirty articles were retained and analysed. VR can be an interesting tool to assess or train team ball sports skills/situations as it allows researchers to control and standardise situations and focus on specific skills/subskills. Studies that used VR in team ball sports still have some limitations, mainly due to technical issues or study design. This paper also describes the way VR should be used to enhance understanding of performance in team ball sports. Additional suggestions for future research and study design are proposed.
ARTICLE HISTORY

Accepted 3 August 2019

KEYWORDS

Virtual reality; virtual environment; team ball sports; review; sport performance assessment and training

\section{Background}

Dynamic sport situations are complex phenomena, emerging at the confluence of attributes and constraints pertaining to the performer, their environment, and the task performed (Newell, 1986). In team ball sports, much of this complexity arises from changes in the relative position of teammates, opponents and ball on the field, creating significant temporal pressures influencing the efficiency of decision making processes and movement skill implementation. These constraints provide opportunities for coaches to create tools for assessing and training of motor control skills. Specifically, the ability to perceive and act upon relevant cues in sporting situations is a major indicator of sport-specific expertise (Starkes, 2000). Developing this ability is a primary goal of training (Williams, Davids, \& Williams, 1999), achieved through exposure to situations simulating temporal pressures characteristic of real sporting situations (Mann, Williams, Ward, \& Janelle, 2007) However, this aspect of assessing and training is logistically intense since many players may be required to simulate even simple situations, and as a result are seldom implemented (Miles, Pop, Watt, Lawrence, \& John, 2012).

Virtual reality (VR)-based simulations of sport situations are increasingly popular for assessment and training purposes (Bideau et al., 2010) since they offer opportunities to manipulate and/or standardise spatial and temporal constraints of all the virtual environment (VE) features such as players and ball trajectories. It is a technology that allows users to interact with a VE (McMenemy \& Ferguson, 2007) while having high ecological validity and experimental control (Loomis, Blascovich, \& Beall, 1999). In VR, players can be exposed to 3D representations of real captured movements (Brault, Bideau, Kulpa, \& Craig, 2012), and their head movements are tracked in real time to update players' viewpoint. Additionally, experimenters have a complete control over positional parameters, temporal constraints, as well as a choice in feedback quality and quantity. These capabilities enhance the immersive feeling and realism of assessment or training tasks compared to 2D displays (Shim, Carlton, \& Kwon, 2006) through what is referred to as the presence (i.e. the feeling of being physically present in the VE (Barfield, Zeltzer, Sheridan, \& Slater, 1995; Sanchez-Vives \& Slater, 2005)) and embodiment (i.e. the feeling of being embodied in one's avatar (Kilteni, Groten, \& Slater, 2012)). These VR-based applications are also a source of motivation and engagement that makes them particularly interesting for training but it raises questions about its persistence over time (Lalmas, O'Brien, \& Yom-Tov, 2014).

Based on VR-specific literature, two features appear important to create realistic and immersive VE: stereovision and adaptive viewpoint. First, although some monocular cues (e.g. occlusion, relative size) can contribute to depth perception (Cutting, 1997; Hillis, Watt, Landy, \& Banks, 2004), such pictorial cues generally do not provide precise quantitative information about depth (Kim, Angelaki, \& DeAngelis, 2016). Stereovision (also referred to as binocular vision or stereoscopic vision) then maximises the number and nature of visual cues, and increases the presence (Craig, 2013; Howard, 2012) and embodiment (Kilteni et al., 2012) of participants interacting with a VE. For instance, Hale and Stanney (2006) showed participants with low stereo acuity can experience a comparable sense of presence as normal sighted individuals, with no increase in adverse effects when viewing through stereoscopic displays. Systems such as CAVE (Cave Automatic Virtual Environment, a projection-based VR display which consists in an immersive VR room where walls, floor and ceiling act as giant monitors) or HMD (Head Mounted Display) offer both stereovision and adaptive viewpoint. Improving the sense of presence (Hale \& Stanney, 
2006; Hendrix \& Barfield, 1996; IJsselsteijn, de Ridder, Freeman, Avons, \& Bouwhuis, 2001; IJsselsteijn, de Ridder, Hamberg, Bouwhuis, \& Freeman, 1998; Snow \& Williges, 1997), and perception of object size (Davis \& Hodges, 1995; Hale \& Stanney, 2006; Luo, Kenyon, Kamper, Sandin, \& DeFanti, 2007) is essential for team sports situation (although not always replicated, e. g. Knapp and Loomis (2004); Interrante, Ries, Lindquist, Kaeding and Anderson (2008)). As a consequence, it seems interesting to focus on stereoscopic systems. Second, developing accurate $3 \mathrm{D}$ motion perception requires participants to receive visual consequences of their actions, and adaptive viewpoint has a wide role to play Fulvio and Rokers (2017). Microscopic head movements might indeed provide reliable motion parallax information (Aytekin \& Rucci, 2012; de la Malla, Buiteman, Otters, Smeets, \& Brenner, 2016) and participants in a VE may use this information, even in an unconscious manner. Additionally, motion parallax can provide a good perception of depth, and is important in many sporting situations, where the player typically moves (Miles et al., 2012). In our context of team ball sport, it thus seems important to provide players stereo depth cues and adaptive viewpoint.

Therefore, the ability to create standard and reproducible sport situations makes VR an attractive and increasingly popular tool for the assessment and training of skills, particularly with the complexity of team sports. To this end, we aimed at exploring the way VR/VE were used for assessment and/or training in team ball sports situations.

\subsection{Objectives}

The three main objectives of this review are (1) to provide an overview of methodologies and outcomes of research studies using VR with stereovision and adaptive viewpoint conducted in the context of team ball sports; (2) to better evaluate the potential interest of using VR to analyse or train team ball sports situations and (3) to identify limitations, gaps in knowledge, and remaining scientific challenges in order to propose perspectives and future directions for researches in team ball sports and VR.

\subsection{Search methods}

Studies were included in the review if: (1) they used immersive VR with stereoscopic display; and (2) at least one team ball sport was explored. Studies were excluded from the review if: (1) they were not published in an indexed scientific journal; (2) they did not involve human participants; (3) they were not written in English; (4) team ball sport was only a tool and not the main subject of the study. As discussed before, in the specific context of team ball sports, we made the choice to focus only on stereoscopic systems.

For this review, the MEDLINE and Web of Science Core Collection databases were searched, using predefined combinations of keywords (virtual reality OR virtual environment OR virtual environments) AND (sport OR ball OR handball OR soccer OR football OR rugby OR basketball OR baseball OR softball OR volleyball OR lacrosse OR cricket OR hockey OR netball), with no restriction for publication time. The literature research ending date was 25 September 2018.
Additional sources were gained by screening the reference lists of all included studies. Even if only papers published in scientific journals were considered and selected in the review since they generally contain the more descriptive works, some valuable conference papers (from important conferences in VR such as the IEEE Virtual Reality, Computer Animation and Social Agents, or ACM Symposium on Virtual Reality Software and Technology conferences for example) will also be mentioned (e.g. Ruffaldi et al. (2011b); Fribourg, Argelaguet, Hoyet and Lécuyer (2018)) to discuss ideas and statements proposed here.

\subsection{Overview of selected studies}

After removing duplicates, 1084 articles were identified and screened for eligibility. During screening, titles and abstracts of identified studies were reviewed independently by two authors, to ensure all studies matched inclusion and exclusion criteria. If the two authors did not agree on one article, a third author looked at the article to decide whether or not it should be included. Authors of a specific article were contacted when additional information was needed, or when there was a doubt on a specific point. Abstracts of 183 articles were explored and 47 articles were fully read. Finally, 30 studies were retained for analysis. Figure 1 illustrates the PRISMA (Preferred Reporting Items for Systematic reviews and MetaAnalyses) flow diagram for the search (Moher, Liberati, Tetzlaff, Altman, \& Group, 2009).

Relevant methodological characteristics and main results of retained studies are presented in Table 1 . Use of the $\emptyset$ symbol indicates one of the fields was not applicable. Specifically, for each study, this table sums up: the sport(s) being explored, main goal, study design, VR device used, participants' characteristics, statistical analysis performed, and main results (qualitative and quantitative) obtained. Of the 30 studies included for analysis, 8 focused on handball, 7 on rugby union, 8 on soccer, 4 on baseball/softball, 1 on basketball, and the remaining three were more general works on various team sport and VR. One study explored two team ball sports: handball and rugby union (Bideau et al., 2010). None of the studies had more than one participant performing the task at the same time (i.e. no interaction between real participants during the task).

To better describe the interest of VR for team ball sports, our analysis was structured around three main questions: Can VR be used for skills assessment and training? How to setup VR feedbacks for assessment and training? How could VR help giving cues to and training players in team ball sports performance?

Among the 30 studies retained in this review, three studies looked at the potential of VR for skills assessment and training, seven explored the way to setup feedbacks and two the interest of guidance for training. Additionally, interaction between participant and environment was often explored, whether main interaction was with ball (10 studies), players (4) or both players and ball (4). Finally, three studies offered general discussion and/or overview of VR and its application in the context of sport. Among the 30 selected studies, four explored two of those topics at the same time. 


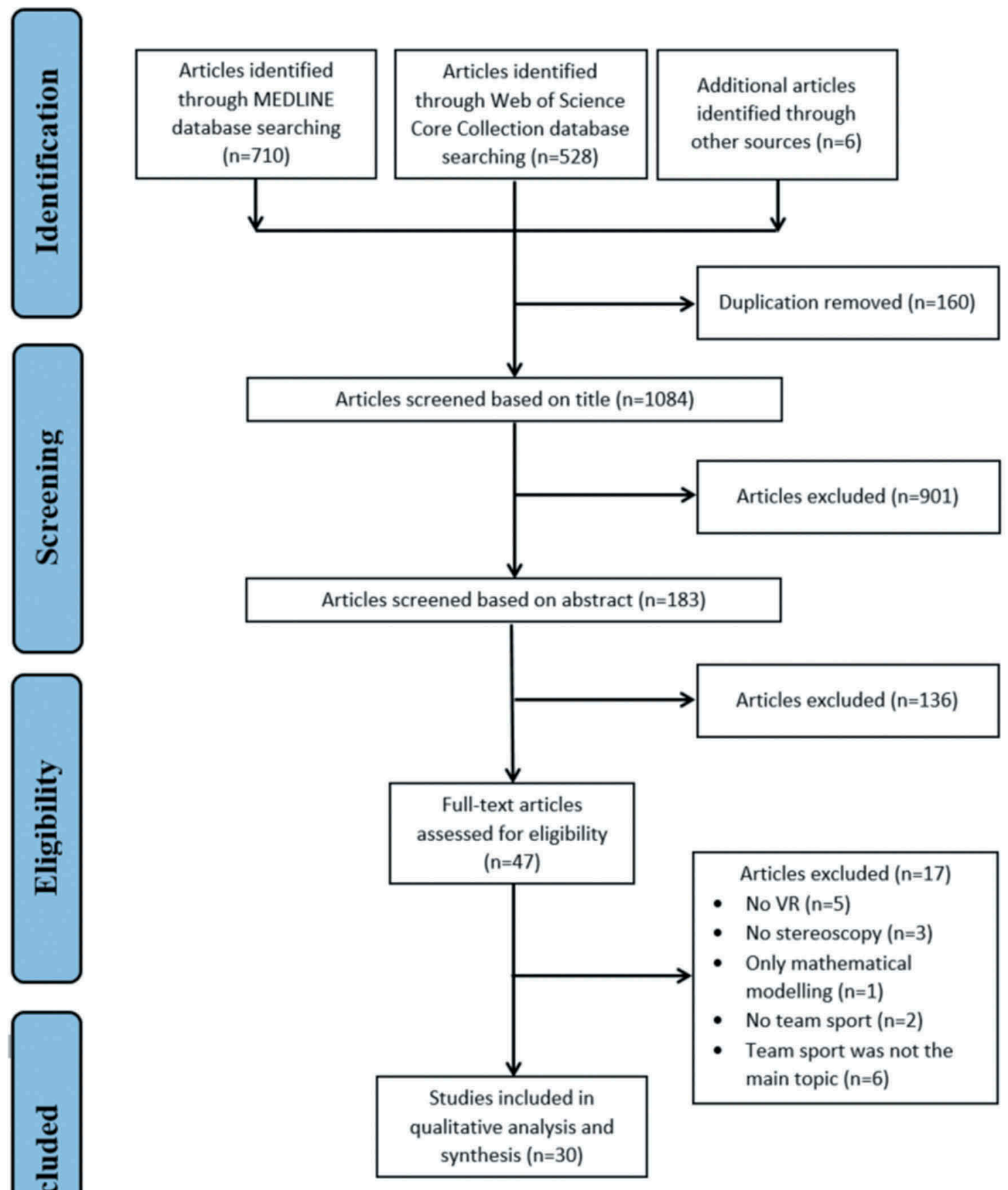

Figure 1. PRISMA flow diagram for the systematic review of the use of virtual reality in team ball sports.

\section{Can VR be used for skills assessment and training?}

The quality of VR is often related to its ability to produce a highlevel of presence to participants. Some authors thus assessed this immersive feeling in VR by using questionnaires (Usoh, Catena, Arman, \& Slater, 2000). They showed that their usefulness may be questionable for the comparison of experiences across environments, such as in immersive virtual and real ones.
To propose an objective assessment of VR setup to analyse sports performance, it is important to verify that players behave the same way in virtual and real environments and that their perception and action are coherent: it is known as behavioural realism. Bideau et al. (2003) evaluated this behavioural realism by comparing the physical performance of a handball goalkeeper facing a real thrower or its virtual avatar. No significant differences were observed on their reaction times, and the 


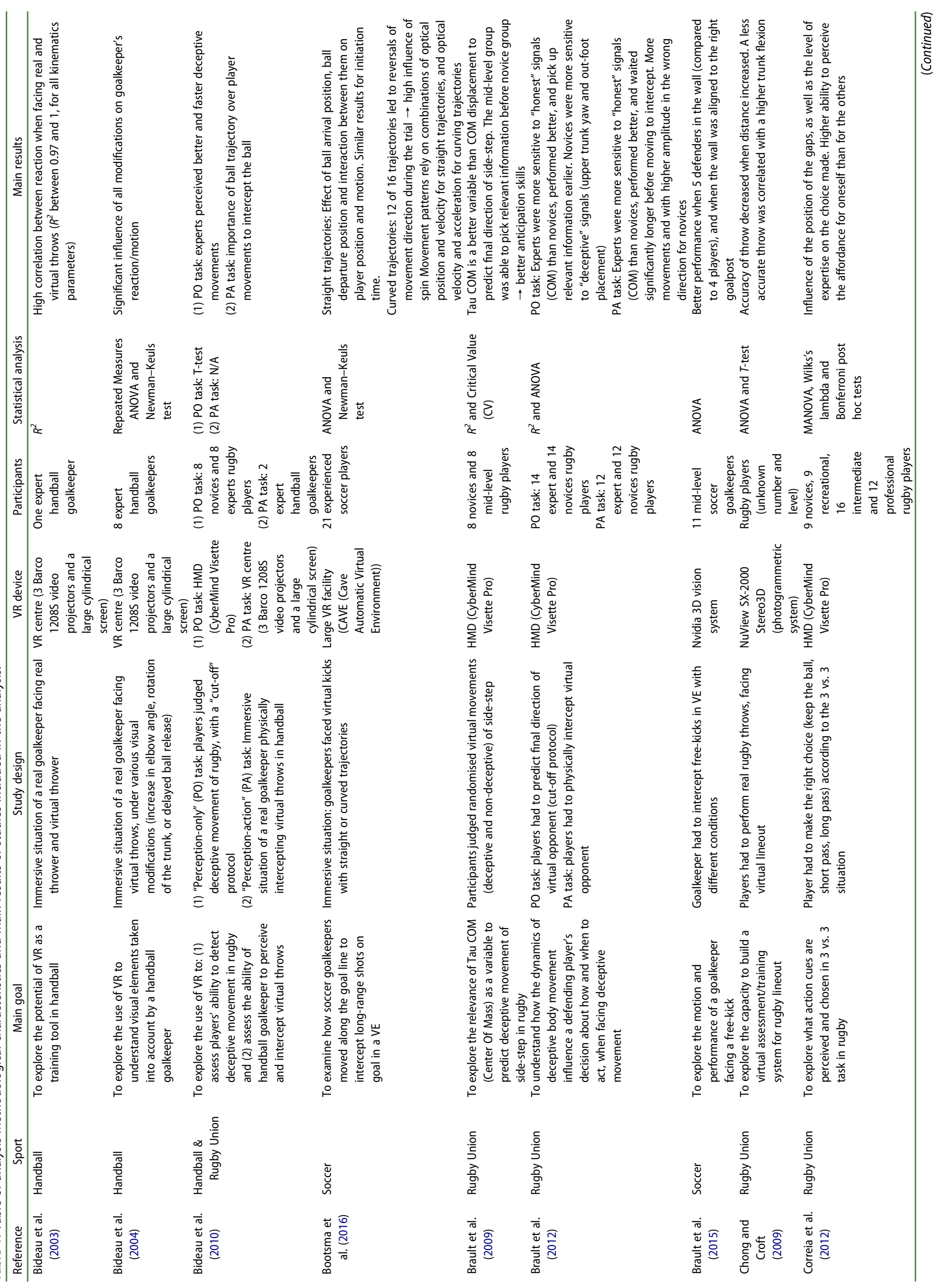


JOURNAL OF SPORTS SCIENCES $\Rightarrow 5$

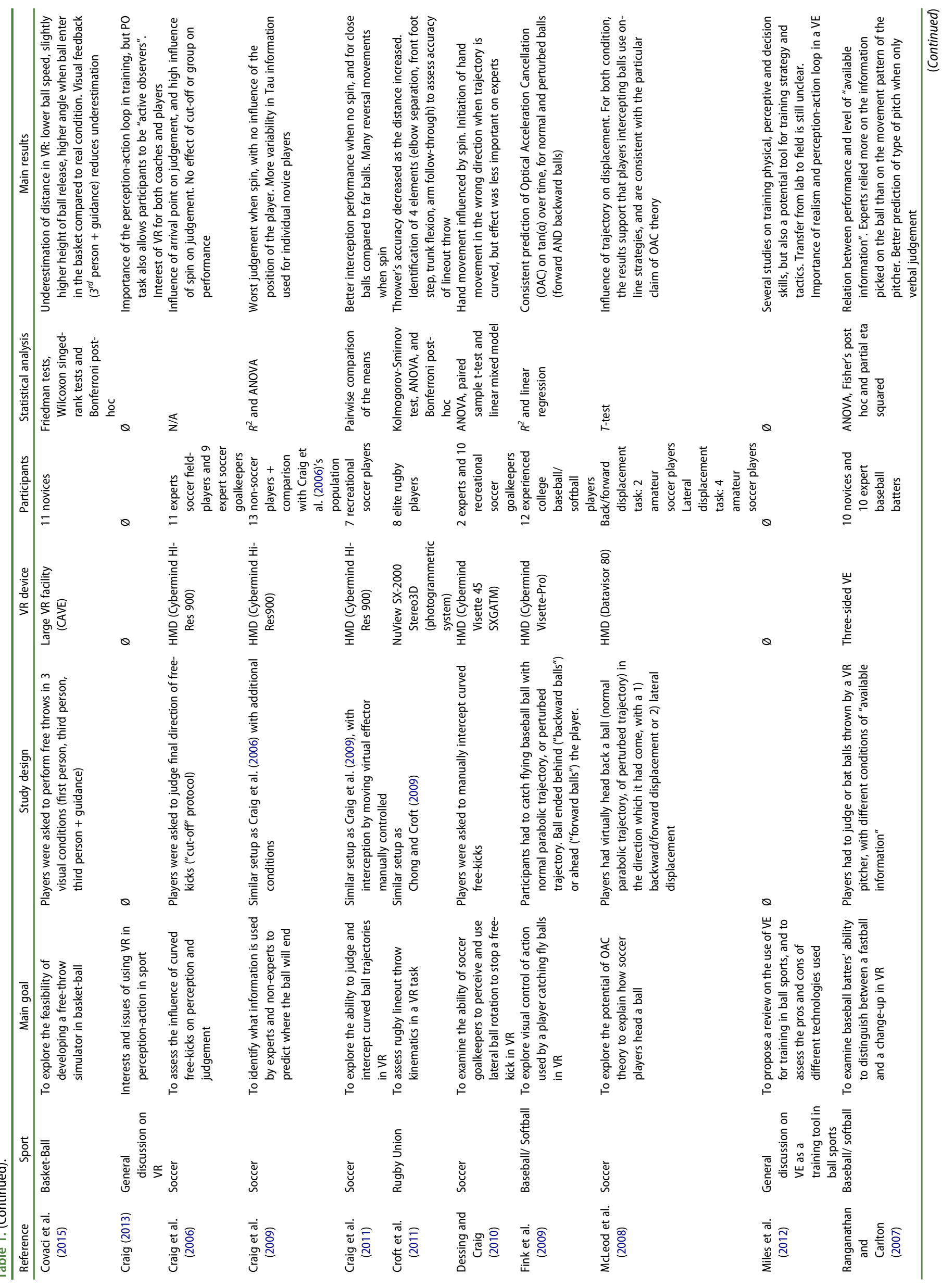




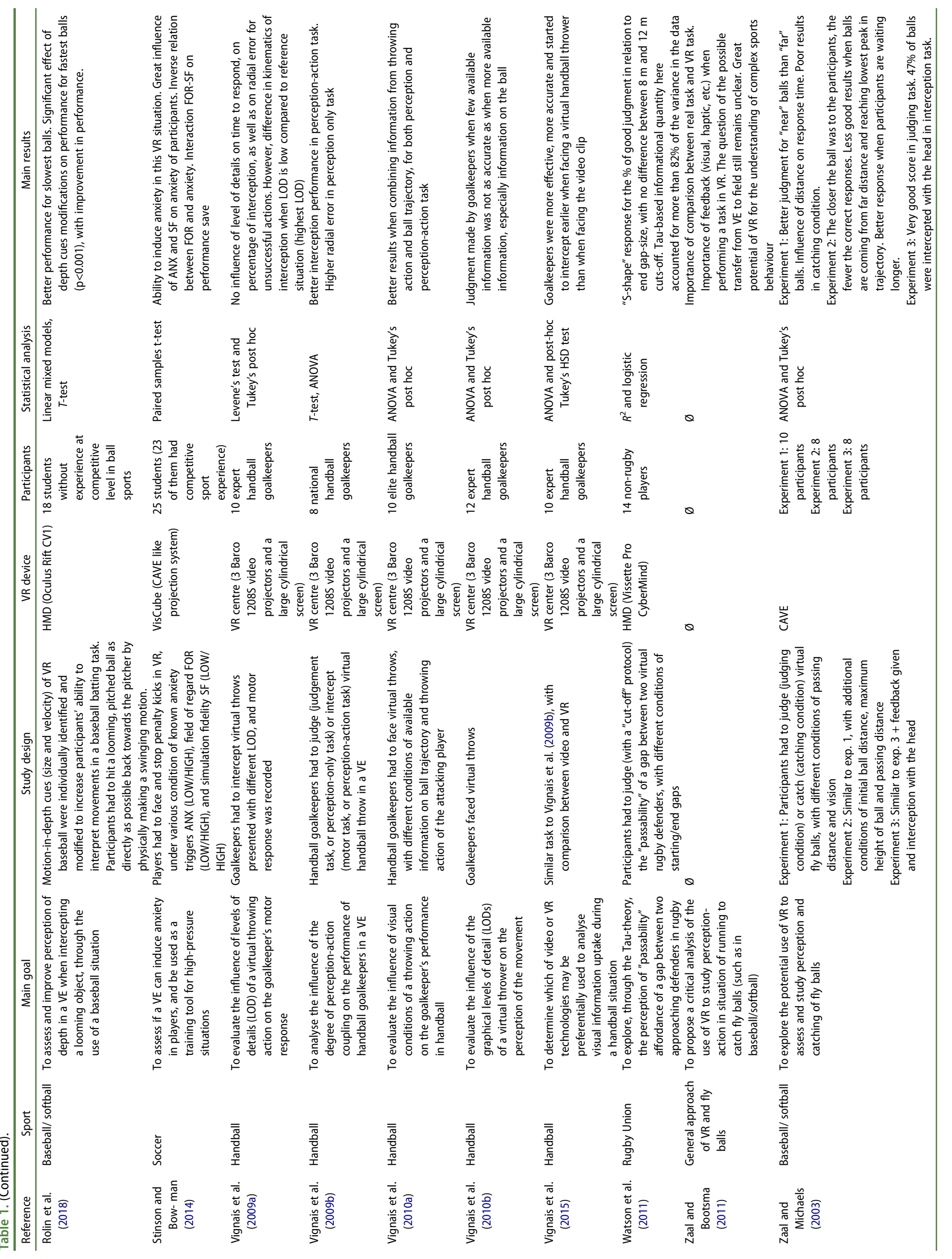


motion of their intercepting arm and leg were highly correlated in both conditions ( $R^{2}$ between 0.97 and 0.99 ).

Moreover, Vignais, Kulpa, Brault, Presse and Bideau (2015) showed that handball goalkeeper performance increased when facing throws in a 3D VE compared to 2D video clips. The stereoscopic information available in VE condition may be a major factor to explain these results. Mazyn, Lenoir, Montagne and Savelsbergh (2004) indeed found that negative effects of a lack of stereovision increase when temporal constraints increase. As handball throwing actions (and in a more general way, most of sport situations) are often time-constrained, it is possible that, when facing video clip, goalkeepers need more time to perceive relevant information and successfully intercept the ball. In addition to stereovision, adaptation of the player's 3D viewpoint is an important factor since it allows to perceive different visual cues necessary to correctly judge situation (Ragan, Kopper, Schuchardt, \& Bowman, 2013). Finally, several authors showed that motor skills can be trained in a more efficient way in VR than in real, by decoupling skills into subskills (Bardy, 2011; Bardy, Delignières, Lagarde, Mottet, \& Zelic, 2010; Bergamasco, Bardy, \& Gopher, 2012). These training accelerators allowed participants to learn skills under conditions not possible in real situation: a juggler more quickly learned how to synchronise his hands thanks to controlled ball trajectories at low speed. Taken together, these elements suggest that VR can be used on sports performance analysis and training when setup is based on stereovision and head tracking (viewpoint adaptation).

In addition, some authors explored the interest of VR for psychological factors. Stinson and Bowman (2014) indeed proposed to investigate the potential of VR to train players in highpressure situations, by means of a penalty kick simulation in soccer. Based on questionnaires evaluation, they found it was possible to induce anxiety in the VR situation they used, and in particular, there was a high influence of environment fidelity on anxiety. Additionally, reduction in visual field of vision induced a reduction in visual distractors (i.e. peripheral distractors), usually related to high-pressure situations. As the impact of anxiety on performance is not the same for everyone (anxiety can be leveraged by some players, or strongly deleterious for others), there is no single approach to explain and model the relationship between performance and anxiety in sport. To this end, it appears that a combination of parameters is important to better understand this relation in a single individual. However, it seems reasonable to think players with strong response to anxiety would benefit from VR sport psychology training programme, such as it is done for phobia treatment. This approach thus provides ideas on which parameters a simulator should focus on, in order to train a specific skill and individualise the training, as previously explored in $10 \mathrm{~m}$ Olympic pistol shooting for example (Argelaguet Sanz, Multon, \& Lécuyer, 2015).

These studies showed that VR can be used to assess and train team sport situations since it allows similar or even better (see for example Bergamasco et al. (2012)) performance in virtual and real situations, and that VR can have a psychological impact on players. Therefore, studies may involve stereoscopic vision and 3D adaptive viewpoint, and focus on the skill to assess/train with limited visual distractors in the VE.

\section{How to setup VR feedbacks for assessment and training?}

VR can be used to assess and train team sport situations but what are the right feedbacks that must be provided to immersed players? This section describes studies that explored the nature of feedbacks and their impact on assessment and training.

To determine the minimal level of graphical details (LOD) required for sports performance application in VR, Vignais et al. (2009a) placed 10 handball goalkeepers in front of virtual throwers with 5 graphical representations (see Figure 2). They found no difference on global goalkeepers' motor performance whatever the LOD. Even if purpose and experimental settings were different, this result gives new highlights about the statements by Johansson (1973) who showed that the motion cues can be read even with only dots representing the joints. However, a deeper analysis showed different motor strategies with the lowest LOD, what could be explained by the change of the well-known ball size and the important reduction of expansion phenomenon. In another study with 12 professional goalkeepers, authors showed that, even if players took information on both player and ball, information available on the ball was very important to accurately identify direction of ball and intercept it (Vignais et al., 2010b). The behavioural realism thus does not require a high quality of graphical rendering of the VE but it is important to preserve the original size of the ball. This result is

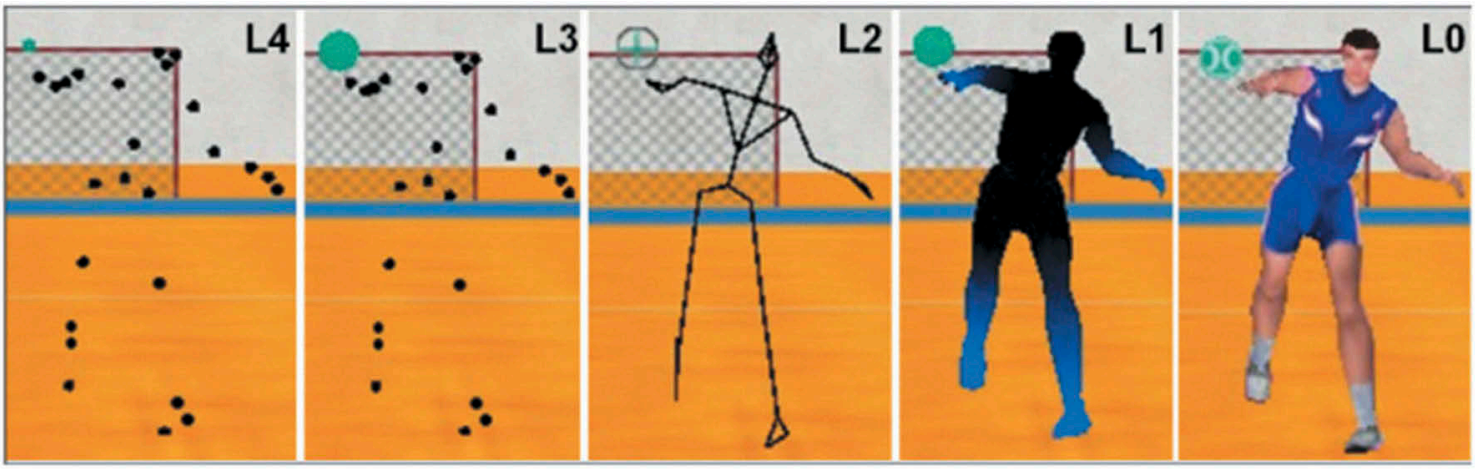

Figure 2. Different Level of Details (LODs) used by Vignais et al. (2009a): a textured reference level (L0), a non-textured level (L1), a wire-frame level (L2), a point-lightdisplay (PLD) representation (L3) and a PLD level with reduced ball size (L4). 
particularly interesting since a reduction in stimulus information may ease the training of perceptual invariants in a task (Farrow, 2013; Lintern, Roscoe, \& Sivier, 1990). On the other hand, a recent study by Fukuhara, Ida, Ogata, Ishii and Higuchi (2017) showed that, in a task where they had to anticipate their opponent's shot direction, skilled tennis players were affected by the richness of graphical information on bodily cues, whereas novice players were not. This suggests that skilled players and novices may not use the same visual cues, and that setup should be adapted according to the population's level of expertise.

Another important component of VR is the viewpoint used to interact with the VE. Previous literature showed that body ownership in VR can be obtained in different viewpoints (Galvan Debarba et al., 2017), and VR can offer both coaches and players the ability to adapt viewpoint, in order to analyse interaction between players or develop and improve competition strategies (Craig, 2013). This provides new possibilities for assessment and training, as many coaches are now looking for new training tools to improve performance, decisionmaking skills, motor control skills, as well as strategy and tactics (Miles et al., 2012) of players. To explore the impact of viewpoint on the performance of novice players, Covaci, Olivier and Multon (2015) designed a VR free-throw simulator in basketball, and compared three conditions: first-person perspective (1PP); third-person perspective (3PP) and thirdperson perspective + visual guidance feedback $(3 P P+$ guidance) which added ellipses to guide the user to the ideal trajectory and speed of throw. No difference in global performance was found between the conditions, suggesting that the viewpoint did not impact performance, although authors highlighted different motor strategies of players. More natural motor behaviour was found in 3PP and 3PP + guidance conditions, with better effect when guidance was present. This may also be due to the fact that participants needed a period of familiarisation and an increase in practice to get comfortable with VR system.

However, it has also been shown that handball goalkeepers better perceive deceptive movements when placed in a firstperson viewpoint compared to a side view (Cañal-Bruland, van der Kamp, \& van Kesteren, 2010). In situations involving active constraints coming from the environment, it may be more interesting to perform the task with a first-person viewpoint. Moreover, viewpoint to use may also depend on the task performed (e.g. intercepting vs. throwing) or on participants' level of practice and expertise.

VR allows to completely control the VE and thus gives the opportunity to add feedbacks, independently from the viewpoint used, to guide players during their training. However, more details on the use of feedbacks in the field of team ball sports are needed, as it has already been done in other sports such as golf (Kelly, Healy, Moran, \& O'Connor, 2010) or rowing (Ruffaldi et al., 2011a,b).

\section{How could VR help giving cues to and training players in team ball sports performance?}

Previous sections showed that VR can immerse players in situations close to real field. Moreover, it allows the creation of virtual situations that can be different from real ones, even impossible to reproduce in real, and can so offer a new generation of training tools. This section concretely describes how VR is currently used for team ball sports analysis and training.

\subsection{Interaction with ball}

In the context of team ball sports, intercepting the ball is an important aspect of performance. To this extent, couple of studies have looked at the ability of players to judge/intercept trajectories or final direction of balls. As an example, Craig, Berton, Rao, Fernandez and Bootsma $(2006,2009)$ or Dessing and Craig (2010) looked at the ability of soccer field-players, soccer goalkeepers and non-soccer players to perceive the final direction of curved free-kicks in soccer. They observed no influence of group but a great influence of spin on judgement: curving ball trajectories induced large errors in perceptual judgement, even in top-level soccer player, because of a lack in perception of lateral rotation of a ball and its influence on ball trajectory. Work by Craig, Bastin and Montagne (2011) confirmed these observations, and suggested that spin effects not only influence the perception of soccer players, but also their physical involvement, in a context where perception and action are linked together. Using similar conditions, Bootsma, Ledouit, Casanova and Zaal (2016) looked at the ability of experienced soccer goalkeepers to intercept virtual kicks in a CAVE and observed similar results, even when participants where physically involved in the task. Moreover, the reversal movements observed when facing the curved trajectories suggested an online control of movement: information picked up strongly influenced the action (Craig et al., 2011). Taking the short time available to judge and act, the importance of a better understanding of this phenomenon in sport seems essential.

Theoretical studies have also explored the Optical Acceleration Cancellation (OAC) theory to analyse how players judge and intercept balls. This approach, initiated by Chapman (1968), supports the idea that players directly couple their movements to visual information (ball acceleration on the retina) in a continuous online control in order to get to the right place at the right time (Zaal \& Bootsma, 2011). In their study, Fink, Foo and Warren (2009) asked twelve experienced baseball/softball players to catch virtual balls, while moving freely in a $12 \mathrm{~m} \times$ $12 \mathrm{~m}$ area. They looked at their ability to accomplish this task when facing normal balls (parabolic path with respect to physics) and perturbed balls (parabolic path until the apogee then linear path towards the same arrival point). They found consistent prediction of OAC on participants' radial movements for normal and perturbed trajectories, highlighting their ability to even respond to physically impossible trajectories. This is in accordance with previous work by McLeod, Reed, Gilson and Glennerster (2008) where participants had to head a virtual ball arriving in front of them, or behind them. It is however important to note that interception performance in Fink et al. (2009)'s study was not particularly good, and authors explained it may be due to the limited field of view of the HMD. However, other studies found performance was not always affected by limited field of view (Brault et al., 2012; Covaci et al., 2015). Zaal and Bootsma (2011) also suggested that this poor performance may be linked to "the choice of having their participants make their catches with a virtual glove": performance could be different when 
interception is performed with the head or with the hand. This was what Zaal and Michaels (2003) investigated when they compared the ability of players to catch virtual ball trajectories in a CAVE, when interception was performed with the hand or with the forehead. They found better results in performance when interception was made with the forehead, and proposed that feedback was essential to help participants improve their performance in judgement/interception. Although feedback was not haptic as in the interception of a real ball, but visual, this appeared sufficient to correctly distinguish successful and unsuccessful interception.

The influence of change in ball speed was also explored by McLeod et al. (2008) during a task where soccer players were asked to move laterally to head virtual balls. Three conditions were used in the experiment: a Normal condition, a Slow condition (where ball speed suddenly decreases at the end) and a Fast condition (where ball speed suddenly increases at the end). Results showed more unsuccessful trials for the Fast condition, and an influence of trajectory and speed on the displacement of players. These results are consistent with the idea of an online regulation of interception. Indeed, when trajectory was perturbed (Fast or Slow conditions), participants had to modify their movement of interception, and the time pressure involved by the Fast condition can explain the poor performance observed. Additionally, authors found that participants used the same strategy in depth, but a range of lateral interception strategies, suggesting that participant can experiment different movements patterns when intercepting flying balls.

Finally, VR was also used to assess and train ball throwing, with photogrammetry to explore kinematics of lineout throw in rugby at three different distances (close, middle, far) (Chong \& Croft, 2009; Croft, Chong, \& Wilson, 2011). The goal was to develop a $3 D$ visual system to assess and train the technique of throwers and their accuracy (Chong \& Croft, 2009) in order to determine the critical body segment movements that led to a higher proportion of successful throws. Main results showed an expected decrease in accuracy of throw when distance increased: the closer the jumper, the more accurate the throw. Moreover, authors highlighted interesting differences in elbow separation, front foot step and trunk flexion between accurate and inaccurate throws (Croft et al., 2011). As the authors explained, the literature on rugby lineout throws is very poor and the results of these two studies provide researchers, players and coaches a good starting point.

\subsection{Interaction with other players}

In team sports, players are interacting with teammates or opponents, and understanding these complex interactions is very difficult. Thanks to its ability to control the situation, VR can offer solutions to better assess and train such interactions.

In one of the first studies where VR was used to analyse a sport situation, Bideau et al. (2004) looked at the visual information picked up by the handball goalkeeper, and used VR to determine the relative influence of opponent's kinematic parameters on the goalkeeper's perception and action. Eight professional goalkeepers were asked to face virtual throws computationally modified to isolate different thrower's kinematics changes, and assess their impact on the goalkeepers' reaction. Results showed that the change of parameters influenced goalkeepers' reactions, validating that they were used by goalkeepers during throws. By its ability to reproduce exactly the same actions or to modify only some parameters, VR gives access to new knowledge about complex interactions between players.

In the context of rugby, Watson et al. (2011) asked 14 novices to judge whether or not they could pass through different gaps between two virtual rugby defenders, i.e. the "passability" of the gaps. An "S-shape" response for the percentage of good judgements in relation to the gap-size was observed. To explain the results, authors explored the interest of Tau, which is a variable that refers to the evolution of a motion-gap during a time interval, defined as the ratio of the current size $x$ of the motion-gap and its rate of closure $\dot{x}$ (see Lee (1998); Brault, Bideau, Kulpa and Craig (2009); Craig et al. (2009); Watson et al. (2011) for details). They found that Tau may be a relevant informational quantity to judge the "passability" of a gap in rugby ( $82 \%$ of the variance in the data was explained by Tau in this study).

However, participants "were perceiving, not acting", which may lead to issues in the ecological validity of the task. Indeed, having an expertise advantage may not be as important in a "perception-only" task compared to a task where participant had to physically respond (Williams, Davids, Burwitz, \& Williams, 1994). Another study by Correia, Araújo, Cummins and Craig (2012) asked 9 non-rugby players, 9 recreational players, 16 intermediate players and 12 professional players to take part in a 3 vs. 3 situation, in a VE. Participants had to make the right choice according to the situation (Figure 3). As expected, a great effect of expertise on performance was observed: the higher the level of expertise, the higher the performance. Here, professional rugby players were more accurate in distinguish the information specifying the "affordance" (originally defined by Gibson (1979), the "affordance" refers to the opportunities of action suggested by the environment or the object being observed), whatever the gap condition. Additionally, it seems easier to perceive an affordance for oneself rather than for others, and Correia et al. (2012) proposed that differences in optical angles of vision may explain this observation. The overall findings are very interesting since in many team ball sport situations, the ability to play for the team is of great importance. A good example is the major role of fly-half in rugby, who must be able to judge direct effective attacking plays and make the right choice at the right time. As a consequence, his/ her ability to perceive affordances for himself/herself as well as for the teammates is essential. Moreover, as some affordances may be faster or easier to detect than others (Smith \& Pepping, 2010) and can be subject-dependent, this raises the suggestion that ability to perceive affordances might be taken into account in detection of talents.

Brault, Kulpa, Duliscouët, Marin and Bideau (2015) looked at the influence of the number of teammates in the wall, in a freekick situation. Eleven goalkeepers were placed in a CAVE and asked to intercept free-kicks. They found performance was better when five players were in the wall compared to four players. Although there are couple of comments that can be made on the protocol they used (e.g. only one departure and two arrival positions of the ball), the interest of this study 


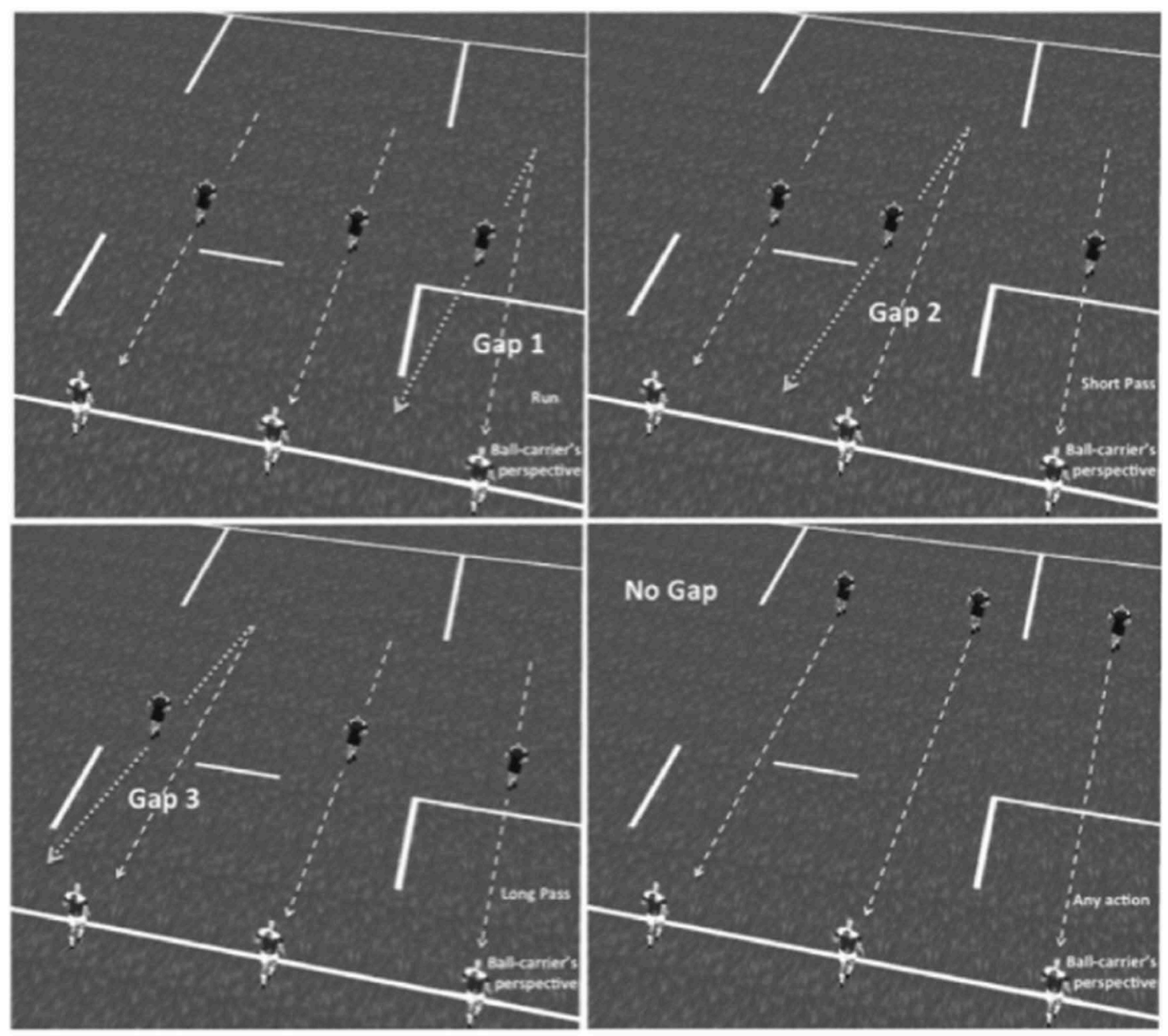

Figure 3. Schematic representation of the different gap conditions used by Correia et al. (2012).

remains in its field-directed substance. However, these results did not explore the potential role of disturbance led by an additional attacker in the wall. Dessing and Craig (2010) proposed that in a free-kick situation, there would be a great interest for the attacking team to add attackers in the defensive wall, in order to strongly disturb the goalkeeper and prevent $\mathrm{him} /$ her from picking visual cues early. Obviously, those attackers must in fine withdraw, bend down or jump according to the kick in order not to counter it.

Interest of VR to explore interaction with opponents has been well established in literature, as it enables participants to face standardised situations through tasks of judgement and/or action. However, most of studies have looked at the mixed interaction with balls and players, a situation often encounter in team ball sports.

\subsection{Interaction with both ball and players}

To study the relative importance of visual information in baseball, Ranganathan and Carlton (2007) looked at the ability of expert and novice batters to judge and bat balls thrown by a virtual pitcher, with different conditions of "available information" (i.e. different conditions of time that ball was visible, and time that the pitcher was visible, see Ranganathan and Carlton (2007) for more details). They asked participants to (1) respond verbally if they were facing a fastball or change-up (uncoupled response mode), or (2) virtually hit the ball with a real bat (coupled response mode). As expected, performance increased when more information was available, which is in accordance with the observations by Bideau et al. (2004) or Vignais, Kulpa, Craig and Bideau (2010a). Another interesting result is that for the coupled response mode, experts were better able to use the first $100 \mathrm{~ms}$ of ball flight independently of the pitcher's kinematics. In addition, the expert batters' stepping patterns were related to the pitcher's kinematics, whereas their swing time was related to the ball speed. These observations may be explained by different points: first, their better ability to perceive and use rotational cues from the ball (Gray, 2002). Second, as skilled pitchers are able to adjust the speed and motion of the ball with only few kinematic changes in the movement pattern, experts may be better at focusing on the ball rather than on the pitcher's movements, thus explaining their capacity not to be fooled by pitcher's pattern of movements. Finally, expert can better adjust their swing to the requirements of the pitch speed and type, in a quick and effective manner (Gray, 2002). To this end, and although no stereoscopy was used (which why 
studies were not included in this review), studies led by Rob Gray offer interesting protocols and results on virtual batting task (for more details, see Gray $(2002,2009,2017,2018)$.

As a consequence, and although some questions still remain (e.g. viewpoint and feedbacks to use, optimal LOD), VR seems to be an interesting tool to assess and train team ball sport situations. With recent improvement in technologies, quality of rendering as well as interaction with VE (players, ball, background, etc.) is now increasingly being explored. To be more specific, we argue technology used in VR now offers the potential to design training/assessment situations where players are facing specific, standardised situation, in an environment and with conditions close to real ones.

\section{Synthesis and future prospects}

In this paper, we identified thirty relevant studies led in the field of VR applied to team ball sports, to better understand the interest and potential of VR as well as its limits and future prospects in this specific field.

First, we found that VR provides reliable assessment and training situations for team ball sports in VR (e.g. Stinson and Bowman (2014); Vignais et al. (2015)), with limited effect of rendering and realism (Vignais et al., 2009a): studies may involve the use of 3D adaptive viewpoint and stereoscopic vision while minimising visual distractors in the VE to better focus on the specific skill to assess and/or train. Second, even though only few studies have looked at how feedbacks should be setup in such situations, the viewpoint to use may depend on the level of practice and expertise of participants, as third-person view offers an easier way to train beginners, and first-person view a better level of "presence", and so, a situation closer to real ones (CañalBruland et al., 2010; Covaci et al., 2015). Craig (2013) also proposed, for example, that coaches could experiment an event or an action, but from the player's viewpoint, and vice-versa. We finally looked at the way VR has already been used in team ball sports. Several studies showed that VR offers unique features to understand how a goalkeeper retrieves information on the opponent in order to intercept a ball in handball (Bideau et al., 2003; Vignais et al., 2009a, 2015) or soccer (Brault et al., 2015; Craig et al., 2006, 2009). Additionally, by controlling all the components of the simulation, VR allows to determine the relative importance of the ball and player motions in the decision-making, in baseball (Ranganathan \& Carlton, 2007; Rolin, Fooken, Spering, \& Pai, 2018), handball (Vignais et al., 2010a) or rugby (Brault et al., 2009, 2012; Correia et al., 2012). Other studies explored how VR can be used to train a player, for example by giving feedbacks to focus on important cues of a situation (Craig, 2013). Finally, VR situation can also be modified online to enhance participants' performance (Rolin et al., 2018) and even help building highly controlled simulators to perform a specific action (Chong \& Croft, 2009; Covaci et al., 2015; Croft et al., 2011) or train under realistic preparation (Düking, Holmberg, \& Sperlich, 2018). However, this topic is recent and there is still a need for more studies to consolidate results already observed.

Although VR appears to be an efficient tool, its use must be carried out cautiously to deal with the technical and study design limits. The first technical limit concerns the latency, the delay between the action performed in VR and the feedback showing its consequences in VE. Hopefully, devices made great improvements and no recent study has reported time-delays issues in their experiment when using new generation of systems. Another limit is the cybersickness (i.e. a feeling of discomfort/sickness) that some participants may experience, which seems to be highly individual dependent. The most important element to reduce this negative effect is adaptation (for complete reviews on side-effects of VE, see Barrett (2004) or more recently Rebenitsch and Owen (2016)). Indeed, regular exposure to VEs helps to adapt to the conditions (Howarth \& Hodder, 2008; Keshavarz, 2016). Yet, when going deeper in this concept, it is still unclear if cybersickness may affect the process of perception, action or learning (Miles et al., 2012). Finally, HMD devices only offer limited field of view, and for instance Fink et al. (2009) have reported that it would explain the poor performance observed in their own study. Nonetheless, other protocols have used similar setup, or limited field of view, and performance was not affected (Brault et al., 2012; Covaci et al., 2015; Fajen, Diaz, \& Cramer, 2011): this may be due to the fact that tasks in these studies required participants to focus on a single element of the scene and thus required a narrow field of view. Additionally, note that the new generation of HMD now reaches a $200^{\circ}$ field of view.

Beyond the technical issues, some limits can be linked to the study design. First, familiarisation with VE and task may be important to reduce the negative effects of VR, but also to succeed in performing the task. Covaci et al. (2015) explained that, in their study, many participants experienced VR for the first time, and reported that training in VR was difficult to get comfortable with, an effect that could be less important with an increase in practice. Second, previous studies have highlighted the importance of designing a sport situation as close as possible to real one, in order to maximise the transfer of skills from virtual to real. On the other hand, works by Bardy et al. (2010), Bardy (2011) and Bergamasco et al. (2012) showed VR can help training of motor skills in a more efficient way than in real, using isolated subskills in a juggling task. This suggests that learning in VR is also possible with approaches that are different from simulating accurately realistic world. Miles et al. (2012) have proposed that, in order to optimise effects of training in VR, the VE should have three features. First, it must enable behavioural realism, where participants perform movements in a similar way than in real situations, to preserve the perception-action loop (Craig et al., 2009). Second, VR must explore a large range of sports, since most current research in sport focuses on endurance sports (Neumann et al., 2017). Indeed, studies in which VR was used in a team ball sport context are limited, as well as tasks performed, and more emphasis on skill-based sports is needed. Especially, many of them focused on assessing or developing participant's ability to perceive cues and trajectories, from the goalkeeper's viewpoint in handball or soccer. Although recent studies have explored several other situations, there is still a lack in the scope of tasks, especially for performance training. The third feature is about the sensory feedback given to participants. Zaal and Michaels (2003) reported that a lack of feedback (e.g. haptic or visual) may explain poor ability perceiving distance in VE. That was corroborated by other results, with underestimation of distance in HMD (Willemsen, Colton, Creem-Regehr, \& Thompson, 2009) or in a CAVE (Covaci et al., 2015). However, when studies 
focused on ball interception such as in handball (Vignais et al., 2010a) or in soccer (Brault et al., 2015), the results showed good performance of goalkeepers. Yet, this observation can be explained by the different nature of the tasks. In ball interception, goalkeepers can regulate their action according to the evolving ball trajectory, and can thus correct early perception errors in an online manner. Couple of studies have used real ball to limit this negative effect of lack of feedbacks in throwing tasks in VR, and recent works by Gray (2017) showed training in a VE can be used to improve on-field performance in a baseball batting task.

Finally, team ball sports situations often involve more than one player, and interactions between partners and/or opponents are essential. Even if shared VR experiences have shown encouraging results in learning interpersonal activities (Varlet et al., 2013) or in enhancing sense of embodiment and engagement (Fribourg et al., 2018), no such study was led in the field of team ball sports. It appears to be a large limitation in situations where players have to continuously interact, and maintain high levels of motivation and engagement that are rarely explored in literature.

Many other aspects could be explored, especially for training in team ball sports. Due to its standardisation and reproducibility features, VR can be used to detect young talents. Coaches may also simulate real situations (for example a freekick by Cristiano Ronaldo in soccer or a service by Gavin Schmitt in volleyball) in order to develop tactical or technical aspects of game in an immersive way. Moreover, an important point is that injured players could maintain their perceptual acuity and ability, by facing virtual pre-defined scenarios without risks of injury (Craig, 2013). Finally, although team ball sports often require interaction between players, no study used a VR system in a cooperative or competitive situation, with more than one participant at the same time. Such multiplayer environment could help researchers better understand how information is perceived and processed collectively.

To conclude, VR and its use in team ball sports has been increasing in the last decades. Most of the studies have looked at the ability to perceive information from the ball/player, and at the resulting action of the player. Although there are still several questions remaining with its use, the future of VR seems wide and plentiful, in the context of team ball sports, and in sport in general. Based on the present review, and on the recent works by Neumann et al. (2017) and Düking et al. (2018), we suggest future researches on VR and team ball sports should:

(1) Better define the term virtual reality that may involve at least interaction with 3D environment, stereoscopic vision and adaptive viewpoint. Recent book by Arnaldi, Guitton and Moreau (2018) offers highlights on the concept of VR and its potential interest in the research world. Additionally, full details on VR system and settings may be given, in order to better assess and understand how VE and study should be setup.

(2) Offer significant period of familiarisation in the VE in order to limit its effects on motion sickness and/or issues in perception of distances.

(3) Use a measure of presence (for example the Slater-UsohSteed (Slater, Steed, McCarthy, \& Maringelli, 1998; Usoh et al., 1999), the Reality Judgement and Presence
Questionnaire (Baños et al., 2000) or the Witmer and Singer (1998) questionnaire) to ensure VE implies real involvement of players in the task.

(4) Better establish potential transfer from skills trained in VR to real-field skills, to ensure this transfer is possible and efficient. This way, VR should be a complementary tool used to easily focus on a specific ability to train, or offer simple and effective situations to overcome difficulties encounter in team ball sports (training sessions for injured players, need for many players to simulate a situation, etc.).

(5) Explore a larger scope of tasks, sports and populations, for example by focusing on young players, or the interaction between multiple participants.

\section{Author Contributions}

\author{
Conception: $\mathrm{CF}, \mathrm{AL}$, RK \\ Literature exploration: $\mathrm{CF}, \mathrm{AL}$ \\ Formal analysis: $\mathrm{CF}, \mathrm{AL}$ \\ Methodology: $\mathrm{CF}, \mathrm{RK}$ \\ Supervision: BB, RK \\ Writing - original draft: $\mathrm{CF}$ \\ Writing - review \& editing: $C F, B B, A L, R K$ \\ Funding acquisition: $\mathrm{BB}, \mathrm{RK}$
}

\section{Acknowledgments}

The authors wish to thank Hugo A. Kerhervé for his input to this work in providing useful comments on structure and discussing content concepts. They also wish to thank Robyn Grunberg for her kind help in English Language review.

\section{Disclosure statement}

No potential conflict of interest was reported by the authors.

\section{Funding}

This work was supported by the Ecole Normale Supérieure de Rennes [Charles Faure is the recipient of a scholarship from "Ecole Normale Supérieure de Rennes" for his doctoral studies];

\section{ORCID}

Charles Faure (D) http://orcid.org/0000-0002-0043-3880

\section{References}

Argelaguet Sanz, F., Multon, F., \& Lécuyer, A. (2015). A methodology for introducing competitive anxiety and pressure in VR sports training. Frontiers in Robotics and Al, 2, 10.

Arnaldi, B., Guitton, P., \& Moreau, G. (2018). Virtual reality and augmented Reality: Myths and realities. Hoboken, NJ, USA: John Wiley \& Sons.

Aytekin, M., \& Rucci, M. (2012). Motion parallax from microscopic head movements during visual fixation. Vision Research, 70, 7-17.

Baños, R. M., Botella, C., Garcia-Palacios, A., Villa, H., Perpiñá, C., \& Alcaniz, M. (2000). Presence and reality judgment in virtual environments: A unitary construct? CyberPsychology \& Behavior, 3(3), 327-335.

Bardy, B., Delignières, D., Lagarde, J., Mottet, D., \& Zelic, G. (2010). An enactive approach to perception-action and skill acquisition in virtual 
reality environments. In Trabajo presentado en la Third International Conference on Applied Human Factors and Ergonomics. Miami, FL, USA.

Bardy, B. G. (2011). Learning new skills in multimodal enactive environments. In BIO Web of Conferences, volume 1 (pp. 00008). EDP Sciences. The International Conference SKILLS 2011 - London, UK.

Barfield, W., Zeltzer, D., Sheridan, T., \& Slater, M. (1995). Presence and performance within virtual environments. Virtual Environments and Advanced Interface Design, 1(1), 473-513.

Barrett, J. (2004). Side effects of virtual environments: A review of the literature. Technical report, Defence Science and Technology Organisation, Canberra, Australia.

Bergamasco, M., Bardy, B. G., \& Gopher, D. (2012). Skills training in multimodal virtual environments. Abingdon-on-Thames, UK: CRC Press.

Bideau, B., Kulpa, R., Ménardais, S., Fradet, L., Multon, F., Delamarche, P., \& Arnaldi, B. (2003). Real handball goalkeeper vs. virtual handball thrower. Presence: Teleoperators and Virtual Environments, 12(4), 411-421.

Bideau, B., Kulpa, R., Vignais, N., Brault, S., Multon, F., \& Craig, C. (2010). Using virtual reality to analyze sports performance. IEEE Computer Graphics and Applications, 30(2), 14-21.

Bideau, B., Multon, F., Kulpa, R., Fradet, L., Arnaldi, B., \& Delamarche, P. (2004). Using virtual reality to analyze links between handball thrower kinematics and goalkeeper's reactions. Neuroscience Letters, 372(1), 119-122.

Bootsma, R. J., Ledouit, S., Casanova, R., \& Zaal, F. T. (2016). Fractional-order information in the visual control of lateral locomotor interception. Journal of Experimental Psychology: Human Perception and Performance, 42(4), 517.

Brault, S., Bideau, B., Kulpa, R., \& Craig, C. (2009). Detecting deceptive movement in 1 vs. 1 based on global body displacement of a rugby player. International Journal of Virtual Reality, 8(4), 31-36.

Brault, S., Bideau, B., Kulpa, R., \& Craig, C. M. (2012). Detecting deception in movement: The case of the side-step in rugby. PLoS One, 7(6), e37494.

Brault, S., Kulpa, R., Duliscouët, L., Marin, A., \& Bideau, B. (2015). Virtual kicker vs. real goalkeeper in soccer: A way to explore goalkeeper's performance. Movement \& Sport Sciences, 89(3), 79-88.

Cañal-Bruland, R., van der Kamp, J., \& van Kesteren, J. (2010). An examination of motor and perceptual contributions to the recognition of deception from others' actions. Human Movement Science, 29(1), 94-102.

Chapman, S. (1968). Catching a baseball. American Journal of Physics, 36(10), 868-870.

Chong, A. K., \& Croft, H. G. (2009). A photogrammetric application in virtual sport training. The Photogrammetric Record, 24(125), 51-65.

Correia, V., Araújo, D., Cummins, A., \& Craig, C. M. (2012). Perceiving and acting upon spaces in a vr rugby task: Expertise effects in affordance detection and task achievement. Journal of Sport and Exercise Psychology, 34(3), 305-321.

Covaci, A., Olivier, A.-H., \& Multon, F. (2015). Visual perspective and feedback guidance for vr free-throw training. IEEE Computer Graphics and Applications, 35(5), 55-65.

Craig, C. (2013). Understanding perception and action in sport: How can virtual reality technology help? Sports Technology, 6(4), 161-169.

Craig, C. M., Bastin, J., \& Montagne, G. (2011). How information guides movement: Intercepting curved free kicks in soccer. Human Movement Science, 30(5), 931-941.

Craig, C. M., Berton, E., Rao, G., Fernandez, L., \& Bootsma, R. J. (2006). Judging where a ball will go: The case of curved free kicks in football. Naturwissenschaften, 93(2), 97-101.

Craig, C. M., Goulon, C., Berton, E., Rao, G., Fernandez, L., \& Bootsma, R. J. (2009). Optic variables used to judge future ball arrival position in expert and novice soccer players. Attention, Perception, \& Psychophysics, 71(3), 515-522.

Croft, H., Chong, A., \& Wilson, B. (2011). Virtual reality assessment of rugby lineout throw kinematics. Sports Technology, 4(1-2), 2-12.

Cutting, J. E. (1997). How the eye measures reality and virtual reality. Behavior Research Methods, Instruments, \& Computers, 29(1), 27-36.

Davis, E. T., \& Hodges, L. F. (1995). Human stereopsis, fusion, and stereoscopic. Human Stereopsis, Fusion, and Stereoscopic Virtual Environments. In Barfield, Woodrow and Furness,III, Thomas A. (Ed). Virtual Environments and Advanced Interface Design, pp. 145-174. New York, NY, USA: Oxford University Press..

de la Malla, C., Buiteman, S., Otters, W., Smeets, J. B., \& Brenner, E. (2016). How various aspects of motion parallax influence distance judgments, even when we think we are standing still. Journal of Vision, 16(9), 8.
Dessing, J. C., \& Craig, C. M. (2010). Bending it like beckham: How to visually fool the goalkeeper. PLoS One, 5(10), e13161.

Düking, P., Holmberg, H.-C., \& Sperlich, B. (2018). The potential usefulness of virtual reality systems for athletes: A short swot analysis. Frontiers in Physiology, 9, 128.

Fajen, B. R., Diaz, G., \& Cramer, C. (2011). Reconsidering the role of movement in perceiving action-scaled affordances. Human Movement Science, 30(3), 504-533.

Farrow, D. (2013). Practice-enhancing technology: A review of perceptual training applications in sport. Sports Technology, 6(4), 170-176.

Fink, P. W., Foo, P. S., \& Warren, W. H. (2009). Catching fly balls in virtual reality: A critical test of the outfielder problem. Journal of Vision, 9(13), 14.

Fribourg, R., Argelaguet, F., Hoyet, L., \& Lécuyer, A. (2018). Studying the sense of embodiment in vr shared experiences. In 2018 IEEE Conference on Virtual Reality and 3D User Interfaces (VR) (pp. 273-280). Berlin, Germany: IEEE.

Fukuhara, K., Ida, H., Ogata, T., Ishii, M., \& Higuchi, T. (2017). The role of proximal body information on anticipatory judgment in tennis using graphical information richness. PloS One, 12(7), e0180985.

Fulvio, J. M., \& Rokers, B. (2017). Use of cues in virtual reality depends on visual feedback. Scientific Reports, 7(1), 16009.

Galvan Debarba, H., Bovet, S., Salomon, R., Blanke, O., Herbelin, B., \& Boulic, R. (2017). Characterizing first and third person viewpoints and their alternation for embodied interaction in virtual reality. PloS One, 12, e0190109.

Gibson, J. (1979). The Ecological Approach to Perception. Boston: Haughton Mifflin.

Gray, R. (2002). Behavior of college baseball players in a virtual batting task. Journal of Experimental Psychology: Human Perception and Performance, 28(5), 1131.

Gray, R. (2009). How do batters use visual, auditory, and tactile information about the success of a baseball swing? Research Quarterly for Exercise and Sport, 80(3), 491-501.

Gray, R. (2017). Transfer of training from virtual to real baseball batting. Frontiers in Psychology, 8, 2183.

Gray, R. (2018). Comparing cueing and constraints interventions for increasing launch angle in baseball batting. Sport, Exercise, and Performance Psychology, 7(3), 318.

Hale, K. S., \& Stanney, K. M. (2006). Effects of low stereo acuity on performance, presence and sickness within a virtual environment. Applied Ergonomics, 37(3), 329-339.

Hendrix, C., \& Barfield, W. (1996). Presence within virtual environments as a function of visual display parameters. Presence: Teleoperators and Virtual Environments, 5(3), 274-289.

Hillis, J. M., Watt, S. J., Landy, M. S., \& Banks, M. S. (2004). Slant from texture and disparity cues: Optimal cue combination. Journal of Vision, 4(12), 1.

Howard, I. P. (2012). Perceiving in depth, volume 1: Basic mechanisms. New York, NY, USA: Oxford University Press.

Howarth, P. A., \& Hodder, S. G. (2008). Characteristics of habituation to motion in a virtual environment. Displays, 29(2), 117-123.

IJsselsteijn, W., de Ridder, H., Freeman, J., Avons, S. E., \& Bouwhuis, D. (2001). Effects of stereoscopic presentation, image motion, and screen size on subjective and objective corroborative measures of presence. Presence: Teleoperators and Virtual Environments, 10(3), 298-311.

IJsselsteijn, W., de Ridder, H., Hamberg, R., Bouwhuis, D., \& Freeman, J. (1998). Perceived depth and the feeling of presence in 3dtv. Displays, 18(4), 207-214.

Interrante, V., Ries, B., Lindquist, J., Kaeding, M., \& Anderson, L. (2008). Elucidating factors that can facilitate veridical spatial perception in immersive virtual environments. Presence: Teleoperators and Virtual Environments, 17(2), 176-198.

Johansson, G. (1973). Visual perception of biological motion and a model for its analysis. Perception \& Psychophysics, 14(2), 201-211.

Kelly, P., Healy, A., Moran, K., \& O'Connor, N. E. (2010). A virtual coaching environment for improving golf swing technique. In Proceedings of the 2010 ACM workshop on Surreal media and virtual cloning(pp. 51-56). Firenze, Italy: ACM.

Keshavarz, B. (2016). Exploring behavioral methods to reduce visually induced motion sickness in virtual environments. In International 
Conference on Virtual, Augmented and Mixed Reality (pp. 147-155). Toronto, Canada.

Kilteni, K., Groten, R., \& Slater, M. (2012). The sense of embodiment in virtual reality. Presence: Teleoperators and Virtual Environments, 21(4), 373-387.

Kim, H. R., Angelaki, D. E., \& DeAngelis, G. C. (2016). The neural basis of depth perception from motion parallax. Philosophical Transactions of the Royal Society B: Biological Sciences, 371(1697), 20150256.

Knapp, J. M., \& Loomis, J. M. (2004). Limited field of view of head-mounted displays is not the cause of distance underestimation in virtual environments. Presence: Teleoperators and Virtual Environments, 13(5), 572-577.

Lalmas, M., O'Brien, H., \& Yom-Tov, E. (2014). Measuring user engagement. Synthesis Lectures on Information Concepts, Retrieval, and Services, 6(4), 1-132.

Lee, D. N. (1998). Guiding movement by coupling taus. Ecological Psychology, 10(3-4), 221-250.

Lintern, G., Roscoe, S. N., \& Sivier, J. E. (1990). Display principles, control dynamics, and environmental factors in pilot training and transfer. Human Factors, 32(3), 299-317.

Loomis, J. M., Blascovich, J. J., \& Beall, A. C. (1999). Immersive virtual environment technology as a basic research tool in psychology. Behavior Research Methods, Instruments, \& Computers, 31(4), 557-564.

Luo, X., Kenyon, R., Kamper, D., Sandin, D., \& DeFanti, T. (2007). The effects of scene complexity, stereovision, and motion parallax on size constancy in a virtual environment. In Virtual Reality Conference, 2007. VR'07. IEEE (pp. 59-66). Charlotte, NC, USA: IEEE.

Mann, D. T., Williams, A. M., Ward, P., \& Janelle, C. M. (2007). Perceptualcognitive expertise in sport: A meta-analysis. Journal of Sport and Exercise Psychology, 29(4), 457-478.

Mazyn, L. I., Lenoir, M., Montagne, G., \& Savelsbergh, G. J. (2004). The contribution of stereo vision to one-handed catching. Experimental Brain Research, 157(3), 383-390.

McLeod, P., Reed, N., Gilson, S., \& Glennerster, A. (2008). How soccer players head the ball: A test of optic acceleration cancellation theory with virtual reality. Vision Research, 48(13), 1479-1487.

McMenemy, K., \& Ferguson, R. S. (2007). A hitchhiker's guide to virtual reality. Boca Raton, FL, USA: CRC Press.

Miles, H. C., Pop, S. R., Watt, S. J., Lawrence, G. P., \& John, N. W. (2012). A review of virtual environments for training in ball sports. Computers \& Graphics, 36(6), 714-726.

Moher, D., Liberati, A., Tetzlaff, J., Altman, D. G., \& Group, P. (2009). Preferred reporting items for systematic reviews and meta-analyses: The prisma statement. PLoS Medicine, 6, e1000097.

Neumann, D. L., Moffitt, R. L., Thomas, P. R., Loveday, K., Watling, D. P., Lombard, C. L., ... Tremeer, M. A. (2017). A systematic review of the application of interactive virtual reality to sport. Virtual Reality, 22(3), $1-16$.

Newell, K. (1986). Constraints on the development of coordination. Motor development in children: Aspects of coordination and control.

Ragan, E. D., Kopper, R., Schuchardt, P., \& Bowman, D. A. (2013). Studying the effects of stereo, head tracking, and field of regard on a small-scale spatial judgment task. IEEE Transactions on Visualization and Computer Graphics, 19(5), 886-896.

Ranganathan, R., \& Carlton, L. G. (2007). Perception-action coupling and anticipatory performance in baseball batting. Journal of Motor Behavior 39(5), 369-380.

Rebenitsch, L., \& Owen, C. (2016). Review on cybersickness in applications and visual displays. Virtual Reality, 20(2), 101-125.

Rolin, R. A., Fooken, J., Spering, M., \& Pai, D. (2018). Perception of looming motion in virtual reality egocentric interception tasks. IEEE Transactions on Visualization and Computer Graphics, 25(10), 3042-3048.

Ruffaldi, E., Filippeschi, A., Avizzano, C. A., Bardy, B., Gopher, D., \& Bergamasco, M. (2011a). Feedback, affordances, and accelerators for training sports in virtual environments. Presence: Teleoperators and Virtual Environments, 20(1), 33-46.

Ruffaldi, E., Filippeschi, A., Bardy, B., Marin, L., Varlet, M., Hoffmann, C., ... Bergamasco, M. (2011b). Training rowing with virtual environments. $B I O$ Web of Conferences, 1, 00078.

Sanchez-Vives, M. V., \& Slater, M. (2005). From presence to consciousness through virtual reality. Nature Reviews Neuroscience, 6(4), 332-339.
Shim, J., Carlton, L. G., \& Kwon, Y.-H. (2006). Perception of kinematic characteristics of tennis strokes for anticipating stroke type and direction. Research Quarterly for Exercise and Sport, 77(3), 326-339.

Slater, M., Steed, A., McCarthy, J., \& Maringelli, F. (1998). The influence of body movement on subjective presence in virtual environments. Human Factors, 40, 469-477.

Smith, J., \& Pepping, G.-J. (2010). Effects of affordance perception on the initiation and actualization of action. Ecological Psychology, 22(2), 119-149.

Snow, M. P., \& Williges, R. C. (1997). Empirical modeling of perceived presence in virtual environments using sequential experimentation techniques. In Proceedings of the Human Factors and Ergonomics Society Annual Meeting, volume 41 (pp. 1224-1228). Los Angeles, CA: SAGE Publications Sage CA.

Starkes, J. (2000). The road to expertise: Is practice the only determinant? International Journal of Sport Psychology, 31(4), 431-451.

Stinson, C., \& Bowman, D. A. (2014). Feasibility of training athletes for highpressure situations using virtual reality. IEEE Transactions on Visualization and Computer Graphics, 20(4), 606-615.

Usoh, M., Arthur, K., Whitton, M. C., Bastos, R., Steed, A., Slater, M., \& Brooks, J. F. P. (1999). Walking $\gg$ walking-in-place $\gg$ flying, in virtual environments. In Proceedings of the 26th Annual Conference on Computer Graphics and Interactive Techniques, SIGGRAPH '99 (pp. 359-364). New York, NY, USA: ACM Press/Addison-Wesley Publishing Co.

Usoh, M., Catena, E., Arman, S., \& Slater, M. (2000). Using presence questionnaires in reality. Presence: Teleoperators and Virtual Environments, 9 (5), 497-503.

Varlet, M., Filippeschi, A., Ben-sadoun, G., Ratto, M., Marin, L., Ruffaldi, E., \& Bardy, B. G. (2013). Virtual reality as a tool to learn interpersonal coordination: Example of team rowing. Presence: Teleoperators and Virtual Environments, 22(3), 202-215.

Vignais, N., Bideau, B., Craig, C., Brault, S., Multon, F., Delamarche, P., \& Kulpa, R. (2009a). Does the level of graphical detail of a virtual handball thrower influence a goalkeeper's motor response? Journal of Sports Science \& Medicine, 8, 501-508.

Vignais, N., Bideau, B., Craig, C., Brault, S., Multon, F., \& Kulpa, R. (2009b). Virtual environments for sport analysis: Perception-action coupling in handball goalkeeping. International Journal of Virtual Reality, 8(4), 43-48.

Vignais, N., Kulpa, R., Brault, S., Presse, D., \& Bideau, B. (2015). Which technology to investigate visual perception in sport: Video vs. virtual reality. Human Movement Science, 39, 12-26.

Vignais, N., Kulpa, R., Craig, C., \& Bideau, B. (2010a). Virtual thrower versus real goalkeeper: The influence of different visual conditions on performance. Presence: Teleoperators and Virtual Environments, 19(4), 281-290.

Vignais, N., Kulpa, R., Craig, C., Brault, S., Multon, F., \& Bideau, B. (2010b). Influence of the graphical levels of detail of a virtual thrower on the perception of the movement. Presence: Teleoperators and Virtual Environments, 19(3), 243-252.

Watson, G., Brault, S., Kulpa, R., Bideau, B., Butterfield, J., \& Craig, C. (2011). Judging the 'passability' of dynamic gaps in a virtual rugby environment. Human Movement Science, 30(5), 942-956.

Willemsen, P., Colton, M. B., Creem-Regehr, S. H., \& Thompson, W. B. (2009). The effects of head-mounted display mechanical properties and field of view on distance judgments in virtual environments. ACM Transactions on Applied Perception (TAP), 6(2), 8.

Williams, A. M., Davids, K., Burwitz, L., \& Williams, J. G. (1994). Visual search strategies in experienced and inexperienced soccer players. Research Quarterly for Exercise and Sport, 65(2), 127-135.

Williams, A. M., Davids, K., \& Williams, J. G. P. (1999). Visual perception and action in sport. Abingdon-on-Thames, UK: Taylor \& Francis.

Witmer, B. G., \& Singer, M. J. (1998). Measuring presence in virtual environments: A presence questionnaire. Presence: Teleoperators and Virtual Environments, 7(3), 225-240.

Zaal, F. T., \& Bootsma, R. J. (2011). Virtual reality as a tool for the study of perception-action: The case of running to catch fly balls. Presence: Teleoperators and Virtual Environments, 20(1), 93-103.

Zaal, F. T., \& Michaels, C. F. (2003). The information for catching fly balls: Judging and intercepting virtual balls in a cave. Journal of Experimental Psychology: Human Perception and Performance, 29(3), 537. 